\title{
Erratum to: Analytical Study of Giant Fluctuations and Temporal Intermittency in an Aggregation Model
}

\author{
Himani Sachdeva · Mustansir Barma
}

Published online: 21 May 2014

(C) Springer Science+Business Media New York 2014

\section{Erratum to: J Stat Phys DOI 10.1007/s10955-013-0899-1}

During the production process, the title for this paper was truncated. It should have read:

Analytical Study of Giant Fluctuations and Temporal Intermittency in an Aggregation Model

The online version of the original article can be found under doi:10.1007/s 10955-013-0899-1.

H. Sachdeva $(\bowtie) \cdot$ M. Barma

Tata Institute of Fundamental Research, Homi Bhabha Road, Mumbai, India

e-mail: himani.sachdeva@gmail.com 